\title{
GESTÃO DA INFORMAÇÃO E DO CONHECIMENTO EM PROJETOS DE PESQUISA E DESENVOLVIMENTO - UM ESTUDO DE CASO
}

\section{RESUMO}

Este artigo tem por objetivo apresentar o Plano de Gestão da Informação e do Conhecimento, que visa a apoiar os processos de criação, aquisição, compartilhamento, armazenamento, (re)utilização, proteção e transferência das informações e conhecimentos, proposto para um Projeto de Pesquisa e Desenvolvimento (P\&D) para a empresa patrocinadora / cliente - Celesc Distribuição, empresa do setor elétrico de Santa Catarina e executado pelo Instituto de Estudos e Gestão Energética - INERGE. O projeto insere-se no programa de P\&D da Agência Nacional de Energia Elétrica - ANEEL, em conformidade com a lei no 9.991/2000 e alterações posteriores. O referencial teórico baseia-se nas áreas da Gestão de Projetos e Gestão do Conhecimento. Metodologicamente caracteriza-se como uma pesquisa de desenvolvimento experimental, intraprojeto e interorganizacional. Os resultados ainda não são efetivos em razão do pouco tempo de implantação do projeto, contudo pode-se inferir que a sistematização das informações e conhecimentos em um único ambiente, além de dar suporte ao desenvolvimento das atividades das equipes do projeto, apoiará os processos de gestão da informação e do conhecimento e, essencialmente, a transferência das informações e dos conhecimentos da empresa executora para a empresa patrocinadora / cliente.

Palavras-chave: Gestão do Conhecimento; Gestão de Projetos; Gestão do Conhecimento em Projetos.

\section{INFORMATION AND KNOWLEDGE MANAGEMENT IN RESEARCH AND DEVELOPMENT PROJECTS} - A CASE STUDY

\section{ABSTRACT}

This article aims to present the Information and Knowledge Management Plan, which aims to support the processes of creation, acquisition, sharing, storage, (re)use, protection and transfer of information and knowledge, proposed for a Research and Development Project for the sponsor enterprise/client - Celesc Distribution, company from the electricity sector in Santa Catarina and executed by the Institute of Studies and Energy Management - INERGE. The project is part of the R\&D program of the National Electric Energy Agency - ANEEL in accordance with the law number no 9.991/2000. The theoretical reference is based on the areas of Project Management and Knowledge Management. Methodologically it is characterized as an interorganizational, interproject research of experimental development. The results are not effective yet, due to the little time of implementation of the project. However it may be inferred that the systematization of the information and knowledge from a single environment, in addition to giving support to the development of the activities of the project teams, will support the processes of information and knowledge management and, essentially, the transfer of the information and knowledge from the executor company and its partners to the sponsor/client company.

Keywords: Knowledge Management; Project Management; Knowledge Management in Projects. 


\section{INFORMACIÓN Y CONOCIMIENTO EN PROYECTOS DE INVESTIGACIÓN Y DESARROLLO - ESTUDIO DE CASO}

\section{RESUMEN}

Este artículo tiene como objetivo presentar el Plan de Gestión del Conocimiento, cuyo objetivo es apoyar la creación, adquisición, distribución, almacenamiento, (re) utilizar, protección y transferencia de información y conocimiento de la información y, propuso un proyecto de investigación y Desarrollo (I + D) para el patrocinador / cliente - Celesc Distribución, la compañía eléctrica de Santa Catarina y ejecutado por el Instituto de Estudios y Gestión de la Energía INERGE. El proyecto forma parte del programa de I + D de la Agencia Nacional de Energía Eléctrica - ANEEL, de conformidad con la ley en 9991/2000 y sus modificaciones posteriores. El marco teórico se basa en las áreas de Gestión de Proyectos y Gestión del Conocimiento. Metodológicamente caracteriza como un desarrollo de la investigación experimental, intraprojeto y entre organizaciones. Los resultados aún no son eficaces debido a una parte del tiempo de ejecución del proyecto, sin embargo, puede inferirse que la sistematización de la información y el conocimiento en un solo ambiente, y apoyar el desarrollo de las actividades de los equipos de proyecto, apoyar los procesos gestión de información y conocimiento y, en esencia, la transferencia de información y conocimiento de la empresa de realizar para la empresa / cliente que patrocina.

Palabras clave: Gestión del Conocimiento; Gestión de Proyectos; Proyecto de Gestión del Conocimiento.

\footnotetext{
${ }^{1}$ Doutora em Administração pelo Université Pierre Mendes France, França. Pesquisador do Estudos e Pesquisas de Eficiência Energética e Sustentabilidade para organizações Privadas, Públicas e do Terceiro Setor. Brasil. E-mail: terezinha.angeloni@gmail.com

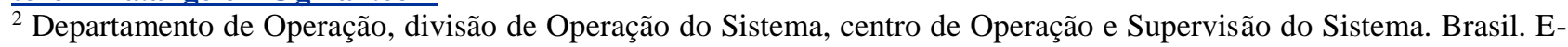
mail: rafaelzh@celesc.com.br

${ }^{3}$ Departamento de Engenharia e Planejamento do Sistema Elétrico. Divisão de Pesquisa e Desenvolvimento e Eficiência Energética. Brasil. E-mail: luizpaf@ celesc.com.br

${ }^{4}$ Doutor em Engenharia de Produção pela Universidade Federal de Santa Catarina - UFSC. Pesquisador do Estudos e Pesquisas de Eficiência Energética e Sustentabilidade para organizações Privadas, Públicas e do Terceiro Setor. Brasil. E-mail: aldo.csnt@gmail.com
} 


\section{INTRODUÇÃO}

Embora tenham surgido, segundo Carneval, Nascimento e Pereira (2005) diversas áreas de conhecimento, processos e ferramentas para apoiar os gerentes de projetos e suas equipes na execução de projetos, são poucos, apesar de crescentes, os estudos no Brasil, e mesmo fora do País, que analisaram o tema da Gestão do Conhecimento em Projetos (Shinoda, 2012).

Entretanto, a informação e o conhecimento vêm sendo considerados, cada vez mais, recursos essenciais no Gerenciamento de Projetos. Para Jamil (2005), os projetos podem ser vistos como processos informacionais ou processos de transformação de informações e conhecimentos. Durante todo seu desenvolvimento, os projetos reúnem e geram informações e conhecimentos; portanto, implementar efetivamente conceitos, práticas, técnicas e instrumentos de Gestão da Informação e do Conhecimento no gerenciamento de projetos pode se revelar um importante diferencial competitivo para o seu sucesso.

O Guia PMBOK® (PMI, 2013) não contempla explicitamente um processo de gerenciamento do conhecimento em sua metodologia, mas em seu item 10 - Gerenciamento das Comunicações do Projeto, aponta que: "O gerenciamento das comunicações do projeto inclui os processos necessários para assegurar que as informações do projeto sejam planejadas, coletadas, criadas, distribuídas, armazenadas, recuperadas, gerenciadas, controladas, monitoradas e finalmente dispostas de maneira oportuna e apropriada" (PMI, 2013, p. 314).

Tal conceito não difere muito dos conceitos da abordagem funcionalista da Gestão do Conhecimento que contempla, dentre outros, os processos de criação, aquisição, compartilhamento, desenvolvimento, retenção, armazenamento, (re)utilização, proteção e transferência das informações e dos conhecimentos (Dhaliwal \& Benbasat, 1996; Gregor \& Benbasat, 1999; Zhao, Kumar \& Stohr, 2001). Esta abordagem privilegia o conhecimento explícito, tratando o conhecimento como "objeto" gerenciável, ou seja, informação.

No apêndice X1 que trata das mudanças na quinta edição do Guia PMBOK® (PMI, 2013, p. 465) encontra-se a seguinte colocação:

Para melhorar o nível de consistência e acrescentar clareza aos dados e fluxos de informações durante a execução do trabalho do projeto, a equipe redefiniu os dados de desempenho do trabalho, as informações sobre o desempenho do trabalho e os relatórios de desempenho do trabalho para alinhá-los com o modelo DIKW (dados, informação, conhecimento e sabedoria) usado na área de gerenciamento do conhecimento.

Com base nas informações acima, pode-se inferir que o Guia PMBOK® contempla a Gestão do
Conhecimento, contudo de forma indireta, estando ela inserida na Gestão da Comunicação, área de extrema relevância, pois as informações e conhecimentos circulam dentro de um projeto, interprojetos, intraorganização ou interorganizações, por meio de um eficiente sistema de comunicação. Só assim os integrantes das organizações e dos projetos poderão dispor de informações e conhecimentos de qualidade e em tempo hábil para apoiar suas ações.

Diante do exposto justifica-se a pertinência deste artigo considerando a importância de avançar naqueles estudos que inter-relacionam as áreas Gestão do Conhecimento e Gestão de Projetos; e define-se como questão de pesquisa: a Gestão do Conhecimento, por meio da definição de um plano de gestão da informação e do conhecimento, pode contribuir para a transferência dos conhecimentos gerados em projetos de pesquisa e desenvolvimento intraprojetos e interorganizacionais?

Este artigo está estruturado em 5 (cinco) seções, sendo a primeira a presente introdução. A segunda apresenta o referencial teórico do estudo. A terceira contempla os procedimentos metodológicos. A quarta descreve o Plano de Gestão da Informação e do Conhecimento. $\mathrm{O}$ artigo finaliza com as considerações finais e recomendações, na quinta e última seção.

\section{GESTÃO DO CONHECIMENTO EM PROJETOS}

Para propor o Plano de Gestão da Informação e do Conhecimento voltado ao projeto de pesquisa e desenvolvimento, faz-se necessário compreender a inter-relação da gestão do conhecimento com a gestão de projeto, o que é um projeto e um projeto de pesquisa e desenvolvimento, bem como quais os tipos de conhecimento, os processos de gestão do conhecimento e a tecnologia que dá suporte à implantação e desenvolvimento do plano.

\subsection{Inter-relação entre as áreas gestão do conhecimento e gestão de projeto}

A administração de projetos sistematizou suas práticas, convertendo-se em uma disciplina nos anos 1980, tendo como líder na consolidação da área o Project Management Institute (PMI), que, em 1996, produziu um Guia do Conhecimento em Gerenciamento de Projetos - GUIA PMBOK® (Pinheiro, Siani, Guilhermino, Henriques, Quental, \& Pizarro, 2006).

O Guia PMBOK® (PMI, 2013), quinta e última versão, apresenta uma metodologia construída com base em 47 processos de gerenciamento agrupados em cinco grupos de processos básicos e não limitadores: iniciação, planejamento, execução, monitoramento e controle, e encerramento. 
A definição de projeto, no citado guia, possui as seguintes características: é um esforço temporário, o que não significa curta duração; tem um início e um término definidos; é empreendido, normalmente, para criar um resultado duradouro que pode ser tangível ou intangível.

Um projeto pode ser realizado dentro e para a organização - intraorganizacional, pode ser executado por uma organização para outra(s) interorganizacional, pode ter seu foco em um único projeto - intraprojeto, ou ser pensado para construir um portfólio de projetos em uma organização orientada para projetos - interprojetos (Shinoda, 2012).

No Manual de Frascati (2013) consta que um projeto pode ser desenvolvido intramuros, no qual a pesquisa é conduzida pela própria empresa, e extramuros, aquelas que são desenvolvidas por instituições de pesquisa públicas ou privadas ou de outras empresas, inclusive empresas do próprio grupo.

O Manual de Frascati, documento referencia quando o assunto é $\mathrm{P} \& \mathrm{D}$, trata da pesquisa e do desenvolvimento experimental que compreende a pesquisa básica, a pesquisa aplicada e o desenvolvimento experimental. Suas definições são aceitas em todo o mundo e seus princípios utilizados como base no Manual de Oslo (2004) e na Lei 11.196/05, também conhecida como a Lei do Bem, que adotam os três tipos de pesquisa acima apresentados.

Seguindo a mesma abordagem, para a ANEEL todo projeto de $\mathrm{P} \& \mathrm{D}$ deverá ser enquadrado em sua fase proposta para desenvolvimento dentro da cadeia da inovação, podendo ser classificada como pesquisa básica dirigida, pesquisa aplicada, desenvolvimento experimental, acrescentando, aos tipos de pesquisas constantes dos Manuais de Frascati e de Oslo e na Lei do Bem, outros tipos como a cabeça de série, lote pioneiro ou inserção no mercado, podendo ser, simultaneamente, nacionalização de produto, desde que agregue algum aprimoramento ou nova funcionalidade, caracterizando o teor de pesquisa e desenvolvimento necessários, respeitada a legislação de propriedade intelectual (ANEEL, 2012).

A ANEEL (2012, p. 53 e 54) assim conceitua os tipos de pesquisa:

\footnotetext{
"Pesquisa Básica Dirigida - fase teórica ou experimental destinada à busca de conhecimento sobre novos fenômenos, com vistas ao desenvolvimento de produtos e processos inovadores [...]. Pesquisa Aplicada - fase destinada à aplicação de conhecimento adquirido, com vistas ao desenvolvimento ou aprimoramento de produtos e processos. Conduz à descoberta de aplicações do conhecimento advindo da pesquisa básica dirigida ou de novos métodos e maneiras de alcançar um objetivo específico [...]. Desenvolvimento Experimental: fase sistemática, delineada a partir de conhecimento pré-existente, visando à
}

comprovação ou à demonstração da viabilidade técnica ou funcional de novos produtos, processos, sistemas e serviços ou, ainda, o aperfeiçoamento do já produzido ou estabelecido [...]. Cabeça de Série - fase que considera aspectos relativos ao aperfeiçoamento de protótipo obtido em projeto de P\&D anterior [...]. Lote Pioneiro fase que considera aspectos relativos à produção em "escala piloto" de cabeça de série desenvolvido em projeto anterior [...]. Inserção no Mercado - fase que encerra a cadeia da inovação e busca a difusão no setor elétrico dos resultados obtidos [...]

Um projeto de Pesquisa \& Desenvolvimento, segundo Pinheiros et al. (2006, p. 3), tem como característica conviver com "um forte componente de incerteza com relação aos seus resultados. Quanto maior o desconhecimento com relação aos resultados esperados, maior o risco relacionado ao projeto". Para esses autores os projetos de $\mathrm{P} \& \mathrm{D}$ se deparam com duas abordagens: uma que está baseada em uma estrutura acadêmica, disciplinar, que estimula a publicação prematura de resultados; e outra, voltada ao desenvolvimento tecnológico, que é multidisciplinar e tem foco no mercado, fazendo emergir a reflexão do que deve ser compartilhado e do que deve ser protegido.

Independentemente do tipo de projeto, é consenso que eles geram dados e informações (PMI, 2013) ou informações e conhecimentos (Jamil, 2005; Shinoda, 2012), surgindo aqui a clássica e controversa diferenciação do que é dado, informação e conhecimento, elementos intangíveis que compõem as bases de armazenamento.

Os dados são considerados elementos brutos, sem significado, desvinculados da realidade. São símbolos e imagens que não dissipam as incertezas. Eles constituem-se na matéria-prima da informação. As informações são consideradas dados com significado, dotados de relevância e propósito (Davenport, 1998). Da mesma forma que o dado é considerado por Davenport (1998) como a matéria-prima para a informação, Malhotra (1993) considera a informação como a matéria-prima para se obter o conhecimento. Para Davenport (1998, p. 19) o "conhecimento é a informação mais valiosa [...] é valiosa precisamente porque alguém deu à informação um contexto, um significado, uma interpretação [...]". O conhecimento pode então ser considerado como a informação processada pelos indivíduos e está basicamente classificado em explícito e tácito.

Ciente da falta de consenso na hierarquia de dado, informação e conhecimento, no guia PMBOK® (PMI, 2013, p. 58), é destacado:

[...] ao longo do ciclo de vida do projeto, uma quantidade significativa de dados e 
informações é coletada, analisada, transformada e distribuída em vários formatos para os membros da equipe do projeto e outras partes interessadas. [...] Os dados coletados são analisados no contexto e agregados e transformados tornando-se informações de projetos [...]. As informações podem então ser verbalmente comunicadas, ou armazenadas e distribuídas como relatórios em vários formatos.

Com o intuito de dirimir dúvidas sobre o que é um dado e uma informação, são apresentados, no citado guia, os seguintes exemplos:

- dados de desempenho do trabalho - são as observações e medições em estado bruto, identificadas durante a execução das atividades de realização dos trabalhos do projeto. Exemplos incluem a percentagem registrada do trabalho fisicamente concluído, medidas de desempenho da qualidade e técnico, datas de início e término das atividades programadas $[. .$.$] .$

- informações de desempenho do trabalho consistem nos dados de desempenho coletados de vários processos de controle, analisados no contexto e integrados com base nos relacionamentos em todas as áreas. Exemplos de informações de desempenho são o status das entregas, o status da implementação das solicitações de mudanças [...].

- relatórios de desempenho do trabalho - a representação física ou eletrônica das informações de desempenho do trabalho são compiladas em documentos do projeto com a intenção de prover argumentos para decisões ou para levantar questões, disparar ações e promover a conscientização. Os exemplos incluem relatórios de status, memorandos, justificativas, notas informativas, painéis eletrônicos, recomendações e atualizações (PMI, 2013, p. 59).

Autores da abordagem interpretativa, como George, Iacono e Kling (1995); Stenmark (2001); Krogh, Ichijo e Nonaka (2001); e Choo (2006), acrescentam que o conhecimento tácito volta a ser informação quando explicitado em algum tipo de mídia.

Independentemente de ser conhecimento explícito ou tácito, eles precisam ser gerenciados para que tragam reais benefícios para os projetos e as organizações, surgindo a questão: o que é Gestão do Conhecimento?

Estudos das já citadas abordagens, a funcional e a interpretativa, percebem de maneira diferente o que é Gestão do Conhecimento. Para os funcionalista Dhaliwal e Benbasat (1996); Gregor e Benbasat (1999); e Zhao, Kumar e Stohr (2001), o desafio é o de organizar o conhecimento como conteúdo visando a sua disponibilização. Para os autores que representam a abordagem interpretativa, como George, Iacono e Kling (1995); Schultze e Boland (2000); Stenmark (2001); Krogh, Ichijo e Nonaka (2001); Choo (2006), o desafio é a criação das condições facilitadoras para que o processo de gestão do conhecimento aconteça no interior das organizações, o que está estritamente relacionado com o ambiente de comunicação.

Pela análise das definições de Gestão do Conhecimento dos autores da abordagem funcionalista pode-se constatar que, de forma geral, elas abordam os processos associados à criação, aquisição, compartilhamento, armazenamento, (re)utilização, proteção e transferência das informações e conhecimentos, utilizando-se muitas vezes de palavras sinônimas. E pela abordagem interpretativa pode-se inferir que é importante criar um ambiente com as condições facilitadoras no qual as pessoas transfiram prontamente o conhecimento, internalizem-no e apliquem-no para criar novos conhecimentos por meio de eficientes formas de as pessoas se comunicarem e ouvirem umas as outras.

Apoiados nas duas abordagens acima citadas, definiu-se Gestão do Conhecimento, no contexto deste trabalho, como um conjunto de processos que apoiam a criação, aquisição, compartilhamento, armazenamento, (re)utilização, proteção e transferência das informações e conhecimentos, assim como a criação de ambiente de comunicação, interação, confiança e satisfação entre os integrantes das equipes das empresas, patrocinadora / cliente, executora e parceiras, visando não apenas à criação da memória do projeto, mas principalmente à criação das condições necessárias para a transferência do conhecimento.

Para Faraco, Mussi, Angeloni (2014) independentemente do contexto, intra ou interorganizacional, a transferência de conhecimento por si só é um processo influenciado por diversos fatores ou variáveis que podem inibi-lo e/ou motivá-lo. Consequentemente, quando se pretende incentivar a transferência de conhecimento torna-se necessário dispensar atenção aos fatores que podem facilitar, retardar ou impedir que os indivíduos compartilhem o que sabem. Dentre os principais fatores destacam: o próprio conhecimento, o transmissor e receptor do conhecimento, o contexto (ambiente) de compartilhamento e a natureza da transferência.

Smit \& Tálamo (2007) destacam que os diferentes tipos de conhecimento, o explícito (informação) e o tácito (conhecimento), não são excludentes, mas interligados e complementares; e ambos necessitam do suporte de práticas, ferramentas e tecnologias de informação para que o seu ciclo se complete.

\subsection{Práticas, ferramentas e tecnologias de suporte à gestão do conhecimento em projetos}

O conhecimento explícito, em linhas gerais, apoia-se na estruturação de repositórios e bases 
(informações), com o objetivo de serem acessados por todos os integrantes de um projeto ou organização; e o tácito tem seu foco na conexão de pessoas por meio de colaboração, criação de comunidades e redes, interações entre pares e pessoas, interação face a face, mídia demonstrativa como vídeo e criação de diretórios de conhecimento.

O guia PMBOK® (PMI, 2013), com seu foco em dados e informações (conhecimento explícito), sugere a criação de uma base de conhecimento corporativa para o armazenamento e recuperação de informações que esta base inclui, mas não se limita a bases de conhecimento de gerenciamento de configuração, bancos de dados financeiros, bases de conhecimento de informações históricas, base de lições aprendidas, bancos de dados de medição dos processos usados para coletar e disponibilizar os dados de medições dos processos e produtos, e arquivos de projetos anteriores.

Shinoda (2012), em estudo teórico (p. 62 e 68) e como resultados de sua pesquisa (p. 215), apresenta uma série de práticas relacionadas ao ciclo de vida do projeto, a saber:

- $\quad$ planejamento - base de lições aprendidas em projetos anteriores, base de conhecimentos do cliente e técnicos (páginas azuis), avaliação de ideias do projeto com base em experiências de projetos, extração de conhecimento de projetos anteriores;

- implementação - aplicação do conhecimento de projetos concluídos para planejamento e orçamento, preparação da proposta, identificação de portadores de conhecimento, organização do projeto, melhores práticas em diferentes estágios de projeto, identificação de especialistas na fase ou atividade específicas, uso de métodos de gestão de projetos consolidados e melhorados;

- encerramento - arquivamento de lições aprendidas e documentos de melhores práticas para projetos futuros, condução de entrevistas pós-projeto, teste e avaliação do conhecimento recém-adquirido, inclusão do conhecimento na base de conhecimentos, transferência pessoal de conhecimentos experienciais para outros times de projeto.

O autor apresenta ainda um relacionamento entre práticas intraprojeto com alguns processos de Gestão do Conhecimento, quais sejam:

- recuperação - alocação de profissional com experiência anterior, apoio de profissional experiente (formal / informal), consulta a materiais de referência de projetos anteriores, consulta a profissionais chaves para indicação de materiais ou pessoas;
- criação / aquisição - desenvolvimento da proposta / plano do projeto, detalhamento do plano do projeto, novos profissionais, benchmarkings (internos / externos), consultorias;

- compartilhamento - reuniões de tomada de decisão sobre proposta ou projeto, passagem de bastão, kick-off, capacitações, comunicações informais, reuniões ou relatórios de status, interações com o cliente, reuniões de alinhamento do time, reuniões de trabalho, divulgação de notícias do projeto, reuniões ou relatório de encerramento;

- armazenamento - equipe do projeto, templates de referência, inserção dos conhecimentos gerados nas bases de dados, arquivamento de lições aprendidas, registro de melhores práticas para projetos futuros (Shinoda, 2012).

Segundo Carneval, Nascimento e Pereira, (2005) e Alves (2015), implementar uma base de informações e conhecimento em projetos tem como objetivo apoiar a criação, aquisição, compartilhamento, armazenamento, (re)utilização, proteção e transferência de informações e conhecimentos para todos os participantes e interessados nos projetos (stakeholders), originando, dentre outros, os seguintes benefícios: centralizar em um único ambiente os dados, informações e conhecimentos relevantes gerados no(s) projeto(s); facilitar o acesso aos documentos; criar a memória do(s) projeto(s); armazenar todo o histórico dos projetos para consulta posterior; apoiar a aquisição e compartilhamento de conhecimentos entre os integrantes do projeto; criar ambientes de interação; padronizar as mensagens utilizadas para o acompanhamento do projeto; incentivar a troca de ideias e garantir feedback; minimizar os riscos durante o projeto; diminuir o nível de tensão proveniente da desinformação; reduzir os custos e retrabalhos com o armazenamento das lições aprendidas; sistematizar e registrar os conhecimentos criados e a serem transferidos.

Contudo, para que os benefícios sejam efetivamente obtidos, faz-se necessário estar atento aos fatores críticos de sucesso, como: a cultura e a estrutura da organização, que pode influenciar de maneira positiva ou negativa a execução dos projetos; o estilo de gestão do coordenador do projeto; o comprometimento dos integrantes do projeto em alimentar as bases; a tecnologia de suporte disponível (conexão e armazenamento) a qualquer hora e por vários meios de acesso (internet, intranet).

Dessa forma, tanto o coordenador do projeto e sua equipe como a(s) organização(ões) envolvida(s) devem estar dispostos a acreditar que a Gestão do Conhecimento pode ser uma ferramenta poderosa para o sucesso não só do projeto em andamento, mas para a continuidade do negócio como um todo. Portanto, a 
ênfase na gestão do conhecimento aliada com a disseminação das metodologias e práticas de gerenciamento de projetos torna evidente a vantagem competitiva que poderá ser obtida em se aplicar essas duas técnicas no desenvolvimento de projetos (Shinoda, 2012).

Com uma rápida abordagem, finaliza-se o presente item discorrendo sobre as partes interessadas em um projeto, tendo como base o guia PMBOK® (PMI, 2013), que inclui:

- o patrocinador - pessoa ou grupo responsável por fornecer recursos e suporte para o projeto e, consequentemente, responsável pelo seu sucesso;

- os clientes e usuários - pessoas ou organizações que aprovarão e gerenciarão o produto, serviço ou resultado do projeto;

- parceiros de negócios - organizações externas que têm relação especial com o projeto, como consultorias especializadas;

- $\quad$ vendedores /fornecedores - empresas externas que assinam um contrato para fornecimento de componentes ou serviços necessários ao projeto;

- empresas certificadoras, outras partes interessadas - entidades de aquisições, instituições financeiras, órgãos públicos reguladores;

- empresa executora - responsável pela execução do projeto interno ou por demanda de outra(s) empresa(s);

- $\quad$ equipe do projeto - gerente do projeto e grupo de indivíduos que atuam conjuntamente na execução do projeto para alcançar os objetivos traçados.

Apresentadas as diferentes práticas, ferramentas e tecnologias de suporte à Gestão do Conhecimento em projetos, passa-se a análise dos diferentes softwares de suporte a Gestão de Projetos.

\subsection{Softwares de suporte à gestão de projetos}

Existe atualmente uma grande diversidade de softwares que servem de apoio à Gestão de Projetos, sendo, portanto, necessária uma análise criteriosa sobre qual deles melhor atende às necessidades da empresa ou do projeto.

Diante da grande diversidade de recursos tecnológicos, institutos de pesquisas, empresas e blogs como JExperts, blog.luz, edutrevizan, fornecem estudos comparativos, análises e tendências de mercado em relação às soluções de tecnologia da informação nas áreas de software, hardware e serviços. As análises giram em torno dos seus valores financeiros, que variam de gratuitos, dependendo da aplicação, a comerciais; software livres ou proprietários; facilidade de uso; e funcionalidades.
As funcionalidades, em linhas gerais, consistem em: gestão de tarefas, gerenciamento de escopo, prazos e custos, painel de controle das tarefas de forma personalizada, gestão de cronograma, diferentes formas de visualização gráfica das informações, gestão e visualização eficaz do caminho crítico, gestão de equipes, gestão de documentos, gestão da comunicação, ferramenta de análise de riscos, criação, medição e controle de indicadores customizados, relatórios de análise de valor agregado, colaboração online.

Dentre os principais softwares destacam-se o GP Web, Runrun, Zoho Projects, Pivolttracker, DotProject, Mantis, Project Builder, Trac, TeamLab, Scrum Half, Artia, Redmine, Smartsheet, Trello, FreedCamp, Asana, Basecamp, Microsoft Project, Oracle Primavera, e Channel.

Vieira (2008) ressalta que, diante da diversidade de softwares existentes no mercado para gerenciamento de projetos, torna-se importante, antes de optar por um, conhecer os seus recursos tecnológicos, limitações, custos, formas de licenciamento, benefícios e confrontá-los com as reais necessidades de sua implementação.

Prado (2009) acrescenta que nem sempre esses softwares possuem todas as funcionalidades necessárias para a gestão completa do projeto, mas o uso de software de gerenciamento de projetos torna-se indispensável para garantir resultados positivos no seu desenvolvimento.

Vicente (2015) apresenta seis critérios básicos na escolha de um software de gerenciamento de projetos: permitir a criação de listas de tarefas de forma simples; e também permitir a priorização dessas listas de tarefas; possibilitar que todos os envolvidos no projeto possam ajudar na solução de problemas e acompanhar a evolução de cada uma das tarefas e o andamento das metas do projeto; mostrar graficamente como está o nível de produtividade da equipe e o quanto cada integrante da equipe está se dedicando ao projeto; permitir a análise dos seguintes indicadores total estimado de custo $\mathrm{x}$ total realizado de custo, consumo de recursos escassos - humanos e financeiros, cronograma previsto $\mathrm{x}$ cronograma realizado; $\mathrm{e}$ possibilitar upload e download de documentos.

Os softwares podem ou não atender à totalidade das necessidades do projeto, mas o mais grave é deixar que os conhecimentos gerados sejam armazenados por cada um dos integrantes do projeto em seus arquivos individuais ou guardados em suas memórias. Tal situação resultará em conhecimentos não explicitados e disponibilizados para todos os integrantes e organizações envolvidos no projeto, interferindo na criação da memória do projeto e consequentemente dificultando $\mathrm{o}$ processo de transferência de conhecimento. 


\section{MÉTODO}

Este artigo tem por objetivo apresentar o Plano de Gestão da Informação e do Conhecimento, que visa a apoiar os processos de criação, aquisição, compartilhamento, armazenamento, (re)utilização, proteção e transferência das informações e conhecimentos, proposto para um Projeto de Pesquisa e Desenvolvimento (P\&D) para a empresa patrocinadora / cliente - Celesc Distribuição, empresa do setor elétrico de Santa Catarina e executado pelo Instituto de Estudos e Gestão Energética - INERGE.

O projeto de Pesquisa e Desenvolvimento, objeto da definição do plano, tem por objetivo desenvolver um sistema integrado para inspeção autônoma de linhas aéreas de transmissão e faz parte do programa de P\&D da ANEEL regulamentado pela lei $n^{0}$ 9.991/2000 e alterações posteriores, que regula a aplicação anual de um percentual da receita operacional líquida- ROL em projetos de pesquisa e desenvolvimento tecnológico do setor de energia elétrica (ANEEL, 2012).

"Projetos de $\mathrm{P} \& \mathrm{D}$ regulados pela ANEEL são aqueles destinados à capacitação e ao desenvolvimento tecnológico das empresas de energia elétrica, visando à geração de novos processos ou produtos, ou o aprimoramento de suas características [...]. Todo projeto de P\&D deverá ser enquadrado em sua fase proposta para desenvolvimento dentro da cadeia da inovação, podendo ser classificada como pesquisa básica dirigida (PB), pesquisa aplicada (PA), desenvolvimento experimental (DE), cabeça de série (CS), lote pioneiro (LP) ou inserção no mercado (IM), podendo ser, simultaneamente, nacionalização de produto, desde que agregue algum aprimoramento ou nova funcionalidade, caracterizando $\mathrm{o}$ teor de pesquisa e desenvolvimento necessários, respeitada a legislação de propriedade intelectual (ANEEL, 2012, p 14)". Caracteriza-se o presente projeto de pesquisa como de desenvolvimento experimental, conforme pode ser visualizado na figura 1, cadeia de inovação da ANEEL.

Apoiados no Manual de Frascati (2013) que serve de apoio a classificação das atividades de P\&D regulados pela ANEEL (2012) caracteriza-se o presente projeto de pesquisa como de desenvolvimento experimental, conforme cadeia de inovação da ANEEL.

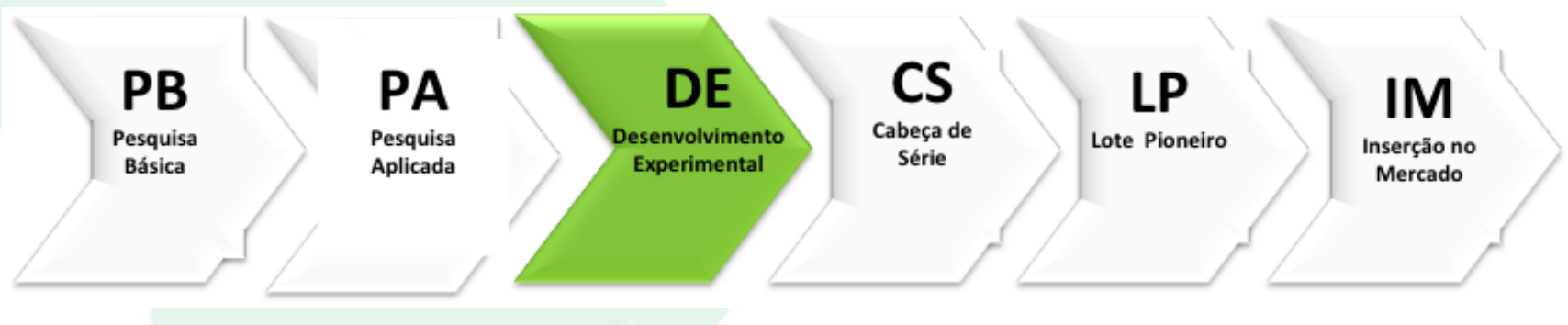

Figura 1 - Cadeia de Inovação da ANEEL

Fonte: Adaptado de Pereira e Caciglieri Junior (2015)

\begin{abstract}
“O Desenvolvimento Experimental trata-se de uma pesquisa delineada a partir de conhecimento préexistente, visando à comprovação ou à demonstração da viabilidade técnica ou funcional de novos produtos, processos, sistemas e serviços ou, ainda, o aperfeiçoamento do já produzido [...].(ANEEL, 2012, p 54).”
\end{abstract}

O estudo caracteriza-se também como intraprojeto e interorganizacional (Shinoda, 2012) ou extramuros (Manual de Frascati, 2013), pois o plano foi desenvolvido apenas para o citado projeto e envolvendo duas empresas, a cliente / patrocinadora e a executora.

A definição do plano, considerando as proposições da questão de pesquisa e o objetivo do projeto, apoia-se, principalmente, na abordagem funcionalista da Gestão do Conhecimento (Dhaliwal \& Benbasat, 1996; Gregor \& Benbasat, 1999; Zhao, Kumar \& Stohr, 2001) que privilegia o conhecimento explícito, não deixando de utilizar, quando oportunas, ações da abordagem interpretativa voltada ao conhecimento tácito (George, Iacono e Kling, 1995; Stenmark, 2001; Krogh, Ichijo e Nonaka, 2001; e Choo, 2006).

Para a elaboração do Plano de Gestão de Gestão da Informação e do Conhecimento foram consultados os 6 (seis) coordenadores e subcoordenadores de áreas da Celesc e do INERGE que, de posse da relação das tarefas constantes do Plano de Gerenciamento do Projeto e de uma relação das principais práticas, ferramentas e tecnologias de gestão da informação e do conhecimento com seus respectivos conceitos, contribuíram com o preenchimento dos quadros das Figuras 3 e 4 . Para 
cada tarefa (figura 3) os coordenadores e subcoordenadores informaram quais documentos seriam gerados no desenvolvimento do projeto resultando nos documentos relacionados a cada uma das tarefas. Os respondentes opinaram ainda sobre quais seriam as melhores práticas, ferramentas e tecnologias da informação seriam as mais pertinentes a serem utilizadas e se o acesso as informações e conhecimentos seriam de uso restrito ou geral. Uma série de pastas (figura 4) foram propostas para armazenar outras informações e conhecimentos gerados e não diretamente relacionados as tarefas do cronograma. A técnica de coleta de dados é, portanto, semiestruturada. O plano resultante atende, portanto, tanto as necessidades da equipe que desenvolve o projeto - intraprojeto, composta por integrantes das duas empresas, como da empresa contratante para a qual os conhecimentos gerados deverão ser transferidos - interorganizações.

Para dar suporte a implantação do plano foi utilizado como software de gerenciamento do projeto o Redmine.

\section{PLANO DE GESTÃO DA INFORMAÇÃO DO CONHECIMENTO - PGIC PROPOSTO}

A Gestão da Informação e do Conhecimento vem sendo considerada, cada vez mais, como recurso essencial no Gerenciamento de Projetos, estando apoiada em informações e conhecimentos, o que justifica a importância de implementar um Plano de Gestão da Informação e do Conhecimento, no presente projeto de Pesquisa \& Desenvolvimento, com os seguintes objetivos.

\subsection{Objetivo}

Definir o Plano de Gestão da Informação e do Conhecimento que visa a apoiar os processos de criação, aquisição, compartilhamento, armazenamento, (re)utilização, proteção e transferência das informações e conhecimentos para o Projeto de Pesquisa \& Desenvolvimento para a Celesc Distribuição, empresa do setor elétrico do Estado de Santa Catarina e executado pelo Instituto de Estudos e Gestão Energética - INERGE.

\subsection{Premissas}

- Tipo de acesso - acesso irrestrito à documentação de projeto e planos de trabalho por todos os integrantes da equipe, sob as cláusulas do acordo de confidencialidade assinado junto à Celesc;

- O software de gerenciamento do plano deverá ser de acesso a todos os integrantes do projeto por meio de internet e intranet, independente do espaço físico em que se encontram.

\subsection{Modelo}

O Plano de Gestão da Informação e do Conhecimento está estruturado conforme demostrado na mostra a Figura 2.

\section{Comunicação}

\section{Projeto}

\section{(gera informação e conhecimento)}
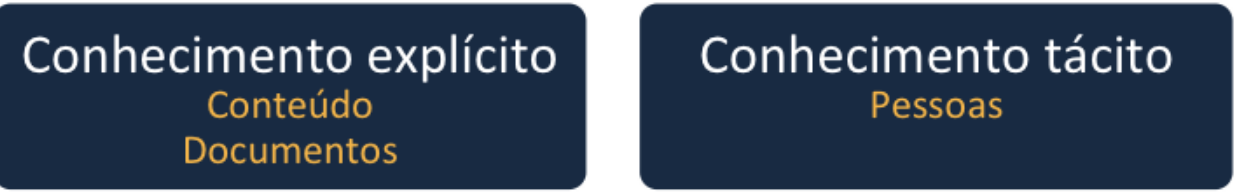

Solução tecnológica disponibilizada

Figura 2 - Estrutura do plano de gestão da informação e do conhecimento Fonte: Elaborada pelos autores 
Para a definição do modelo considera-se que o dado é matéria-prima para a informação; a informação é matéria-prima para o conhecimento; e que esses elementos devem circular entre os integrantes do projeto e das organizações envolvidas por meio de um eficiente sistema de comunicação e da instalação de uma infraestrutura tecnológica adequada.

\subsubsection{Informações e conhecimentos}

As informações e conhecimentos, no presente plano, estão estruturadas em duas partes, uma vinculada às tarefas contidas no cronograma constante do Plano de Gerenciamento do Projeto, cujas etapas foram adaptadas da metodologia de gerenciamento dos projetos PMBOK® (PMI, 2013) (Figura 3), e a outra, composta por um conjunto de pastas que possibilitam o armazenamento de informações e conhecimentos, gerados no decorrer do projeto, mas que não estão diretamente relacionados com as tarefas traçadas no cronograma (Figura 4).

\begin{tabular}{|c|c|c|}
\hline $\begin{array}{c}\text { Tarefa/ } \\
\text { Responsável (eis) }\end{array}$ & Descrição & $\begin{array}{c}\text { Informações e Conhecimento } \\
\text { Gerados } \\
\text { (Documentos Relacionados) }\end{array}$ \\
\hline \multicolumn{3}{|c|}{1 - Iniciação do Projeto } \\
\hline \multirow[t]{2}{*}{$\begin{array}{l}\text { 1.1 Assinatura do Contrato e } \\
\text { Documentos de Base } \\
\text { - Coordenador do Projeto }\end{array}$} & \multirow[t]{2}{*}{$\begin{array}{l}\text { Documentos que formalizam } \\
\text { comprometimento de realização do projeto de } \\
\text { P\&D entre INERGE, CELESC, ANEEL, } \\
\text { assinados, assim como documentos gerais e } \\
\text { técnicos que regem a execução de projetos de } \\
\text { P\&D e o controle de mudanças que } \\
\text { compreenderá a identificação, documentação, } \\
\text { análise e autorização de mudança sobre o } \\
\text { escopo, custos e prazos autorizados para o } \\
\text { projeto. }\end{array}$} & $\begin{array}{l}\text { Abertura do Projeto } \\
\text { - Contrato Assinado } \\
\text { - Ata de Reunião Kick off } \\
\text { - Documento de Aprovação do Projeto } \\
\text { - Projeto Inicial (PRJ) } \\
\text { Alterações Projeto Inicial } \\
\text { - Alterações Contratuais, } \\
\text { - Formulários de Solicitação de } \\
\text { - Mudanças Formulário de Registro de Mudanças } \\
\text { - Planilha de Registro de Mudanças } \\
\text { - Termo de Ajuste }\end{array}$ \\
\hline & & $\begin{array}{l}\text { Doc. orientadores e reguladores }(\mathrm{P} \& \mathrm{D} \\
\text { Celesc / Aneel) } \\
\text { - Manuais } \\
\text { - Normas técnicas } \\
\text { - Regulamentos } \\
\end{array}$ \\
\hline $\begin{array}{l}\text { 1.2 Identificação da Equipe } \\
\text { do Projeto - Base de } \\
\text { Competências } \\
\text { - Coordenador do Projeto } \\
\text { e de Gestão do } \\
\text { Conhecimento } \\
\end{array}$ & $\begin{array}{l}\text { Registrar expertise dos integrantes do INERGE } \\
\text { e equipe(s) de projeto(s), seus contatos e } \\
\text { responsabilidades no projeto, competências } \\
\text { gerais e específicas. }\end{array}$ & $\begin{array}{l}\text { - Formulários Individuais } \\
\text { Competências Preenchidos }\end{array}$ \\
\hline \multicolumn{3}{|c|}{ 2-Especificações } \\
\hline $\begin{array}{l}2.1 \quad \text { Definição dos } \\
\text { Requisitos Funcionais do } \\
\text { Sistema } \\
\text { - Todos os integrantes } \\
\text { projeto }\end{array}$ & $\begin{array}{l}\text { Especificação das missões de inspeção, } \\
\text { definição das categorias de sensores, } \\
\text { detalhamento dos requisitos funcionais do } \\
\text { sistema (informática, } \\
\text { armazenamento e tratamento de imagens). }\end{array}$ & $\begin{array}{l}\text { - Relatório(s) Técnico(s) com o } \\
\text { Detalhamento do Escopo do Projeto e } \\
\text { Requisitos Funcionais do Sistema }\end{array}$ \\
\hline $\begin{array}{l}2.2 \quad \text { Definição dos } \\
\text { Requisitos de Engenharia } \\
\text { - Coordenador de } \\
\text { Engenharia - Inspeção }\end{array}$ & $\begin{array}{l}\text { Levantamento de normas técnicas } \text { e } \\
\text { regulamentos da Celesc, análise da programação } \\
\text { de inspeção e normas e procedimentos da } \\
\begin{array}{llll}\text { Celesc, avaliação dos dados de } \\
\text { georreferenciamento existentes. }\end{array} \\
\end{array}$ & $\begin{array}{l}\text { - Relatório(s) Situacional(is) e de } \\
\text { Requisitos de Engenharia }\end{array}$ \\
\hline $\begin{array}{l}2.3 \quad \text { Definição } \text { dos } \\
\text { Requisitos de TIC e } \\
\text { Tratamento de Imagem } \\
\text { - Coordenador de TIC e } \\
\text { Imagens }\end{array}$ & $\begin{array}{l}\text { Análise de requisitos de informática, } \\
\text { comunicação e armazenamento, especificação e } \\
\text { qualificação do sistema de aquisição de } \\
\text { imagens, análise do ambiente de integração, e } \\
\text { definição do escopo das TIC. }\end{array}$ & $\begin{array}{l}\text { - Relatório(s) de Especificação dos } \\
\text { Sistemas de Aquisição, Transmissão, } \\
\text { Tratamento e Armazenamento de } \\
\text { Dados e Imagens }\end{array}$ \\
\hline 2.4 Projeto & Definição & - Relatório(s) \\
\hline
\end{tabular}




\begin{tabular}{|c|c|c|}
\hline $\begin{array}{l}\text { Preliminar } \\
\text { - Coordenador } \\
\text { Engenharia } \\
\text { Aeronáutica }\end{array}$ & $\begin{array}{l}\text { dimensionamento do sistema de aeronave para o } \\
\text { projeto e componentes. }\end{array}$ & $\begin{array}{l}\text { Descrição Técnica (para compra de } \\
\text { aeronave) Rev 00 } \\
\text { - Documentos Relacionados ao } \\
\text { Desenvolvimento do Projeto }\end{array}$ \\
\hline \multicolumn{3}{|c|}{3 - Detalhamento } \\
\hline $\begin{array}{l}\text { 3.1 Plano de Inspeção } \\
\text { - Coordenador de } \\
\text { Engenharia - Inspeção }\end{array}$ & $\begin{array}{l}\text { Detalhamento do plano de inspeção através da: } \\
\text { definição e hierarquização dos aspectos a serem } \\
\text { inspecionados; definição do trecho piloto e, } \\
\text { definição do Plano de Inspeção e resultados } \\
\text { esperados. }\end{array}$ & $\begin{array}{l}\text { - Plano de Inspeção e Relatório } \\
\text { Situacional do Trecho Piloto }\end{array}$ \\
\hline $\begin{array}{l}\text { 3.2a Definição TIC } \\
\text { TIC e Imagem } \\
\text { - Coordenador de TIC e } \\
\text { Imagem }\end{array}$ & Definição de Tecnologias TIC e Imagem & $\begin{array}{l}\text { - Relatório do Projeto Detalhado da } \\
\text { Solução TIC }\end{array}$ \\
\hline $\begin{array}{l}\text { 3.2b Definição Kit de } \\
\text { Calibragem } \\
\text { - Coordenador de TIC e } \\
\text { Imagem }\end{array}$ & $\begin{array}{l}\text { Definição do Kit de Calibração e Sistema de } \\
\text { Aquisição de Imagens. Estudo e definição de } \\
\text { tecnologias (comunicação, armazenamento, } \\
\text { IHM etc.) }\end{array}$ & $\begin{array}{l}\text { - Relatório do Sistema de Calibração } \\
\text { Desenvolvido }\end{array}$ \\
\hline $\begin{array}{l}\text { 3.3 Definição Sistema de } \\
\text { Aquisição de Imagem } \\
\text { - Coordenador de TIC e } \\
\text { Imagem }\end{array}$ & $\begin{array}{l}\text { Definição do Sistema de Aquisição de Imagens. } \\
\text { (comunicação, armazenamento, IHM etc.) }\end{array}$ & $\begin{array}{l}\text { - Relatório do Kit de Imagens e } \\
\text { Elementos de Referência para } \\
\text { Calibração dos Sensores, Planos de } \\
\text { Qualidade }\end{array}$ \\
\hline $\begin{array}{l}\text { 3.4 Projeto Aeronáutico } \\
\text { Detalhado - ano 1 } \\
\begin{array}{l}\text { Coordenador } \\
\text { Engenharia } \\
\text { Aeronáutica }\end{array} \\
\end{array}$ & $\begin{array}{l}\text { Detalhamento do projeto aeronáutico, incluindo } \\
\text { a análise de sistemas, aeronáutica e software de } \\
\text { guiamento e controle, revisões de design, de voo } \\
\text { e de qualificação (TRR, FRR e FQR) }\end{array}$ & $\begin{array}{l}\text { - Relatório das Especificações } \\
\text { Descrição Técnica (para Compra de } \\
\text { Aeronave) Rev } 01\end{array}$ \\
\hline $\begin{array}{l}\text { 3.4 Projeto Aeronáutico } \\
\text { Detalhado - ano } 2 \\
\text { - Coordenador } \\
\quad \begin{array}{l}\text { Engenharia } \\
\text { Aeronáutica }\end{array} \\
\end{array}$ & $\begin{array}{l}\text { Detalhamento do projeto, incluindo a análise de } \\
\text { sistemas, aeronáutica e software de guiamento e } \\
\text { controle, revisões de design, de voo e de } \\
\text { qualificação (TRR, FRR e FQR). }\end{array}$ & $\begin{array}{l}\text { Relatório(s) de Especificação e } \\
\text { Descrição Técnica (para Compra de } \\
\text { Aeronave) Rev } 02\end{array}$ \\
\hline \multicolumn{3}{|c|}{ 4-Desenvolvimento } \\
\hline $\begin{array}{l}\text { 4.1 Prototipagem Integração } \\
\text { e Teste de Engenharia } \\
\text { - Coordenador de } \\
\text { Engenharia - Inspeção }\end{array}$ & $\begin{array}{l}\text { Acompanhamento da criação dos protótipos e } \\
\text { testes dos sistemas, dos processos de aquisição, } \\
\text { montagem e integração dos equipamentos e } \\
\text { sensores, execução de teste de engenharia. }\end{array}$ & $\begin{array}{l}\text { - Manuais e Relatórios } \\
\text { Acompanhamento e Teste }\end{array}$ \\
\hline $\begin{array}{l}\text { 4.2 Desenvolvimento } \\
\text { Sistemas TIC } \\
-\quad \text { Coordenador de TIC }\end{array}$ & $\begin{array}{l}\text { Desenvolvimento } \mathrm{e} \text { acompanhamento } \\
\text { continuado, controle de desempenho e de } \\
\text { mudanças no sistema TIC, desenvolvimento dos } \\
\text { testes individuais dos módulos. }\end{array}$ & $\begin{array}{l}\text { - Versão Beta dos Sistemas TIC } \\
\text { Plano de Testes Integrados, } \\
\text { Documentação do Desenvolvimento de } \\
\text { Sistemas }\end{array}$ \\
\hline $\begin{array}{l}\text { 4.3 Definição das Técnicas } \\
\text { de Segmentação, } \\
\text { Representação e Base de } \\
\text { Conhecimento (imagens) } \\
\text { - Coordenador de } \\
\text { Imagem }\end{array}$ & $\begin{array}{l}\text { Definição e implementação de técnicas de } \\
\text { segmentação, representação e bases de } \\
\text { conhecimento, comunicação e armazenamento } \\
\text { dos resultados. }\end{array}$ & $\begin{array}{l}\text { - Relatórios das Técnicas de } \\
\text { Segmentação, Representação e Bases de } \\
\text { Conhecimento Implantadas } \\
\text { - Manuais Técnicos }\end{array}$ \\
\hline \multicolumn{3}{|c|}{5 - Prototipagem, Validação e Testes Integrantes } \\
\hline $\begin{array}{l}5.1 \quad \text { Prototipagem, } \\
\text { Integração e Testes } \\
\text { - } \quad \text { Coordenador } \\
\begin{array}{l}\text { Engenharia } \\
\text { Aeronáutica }\end{array} \\
\end{array}$ & $\begin{array}{l}\text { Prototipagem, integração e testes do sistema, } \\
\text { codificação e testes de software, construção, } \\
\text { montagem, instalação, integração e testes de } \\
\text { componentes elétricos, eletrônicos e mecânicos. }\end{array}$ & $\begin{array}{l}\text { - Relatório do Protótipo e Documentação } \\
\text { do Test Readness Review - TRR } \\
\text { - Relatório das Plataformas Integradas, } \\
\text { Software de Controle e Guiamento } \\
\text { Desenvolvidos }\end{array}$ \\
\hline $\begin{array}{lr}5.2 \quad \text { Verificação } & \text { de } \\
\text { Prototipagem } & \\
\text { - } \quad \text { Coordenador } & \text { de } \\
\quad \text { Engenharia } & \mathrm{e} \\
\quad \text { Aeronáutica } & \\
\end{array}$ & $\begin{array}{l}\text { Realização dos testes sucessivos de verificação } \\
\text { de subsistemas e do sistema total de maneira a } \\
\text { viabilizar a liberação para voo. }\end{array}$ & $\begin{array}{l}\text { - Formulário de } \quad \text { Verificação da } \\
\text { Integração } \\
\text { - Documentação do Fligth Readness } \\
\text { Review-FRR }\end{array}$ \\
\hline $\begin{array}{l}\text { 5.3 Validação da Plataforma } \\
\text { VANT } \\
\text { - Coordenador de }\end{array}$ & $\begin{array}{l}\text { Ensaios de voo de abertura e validação do } \\
\text { sistema da aeronave. }\end{array}$ & - Relatório de Ensaios de Validação \\
\hline
\end{tabular}




\begin{tabular}{|c|c|c|}
\hline $\begin{array}{l}\text { Engenharia } \\
\text { Aeronáutica }\end{array}$ & & \\
\hline $\begin{array}{l}\text { 5.4 Testes Integrados } \\
\text { - Todos os integrantes do } \\
\text { projeto }\end{array}$ & $\begin{array}{l}\text { Realização dos testes integrados e verificação do } \\
\text { desempenho dos sistemas TIC em condições } \\
\text { controladas, complementação da documentação } \\
\text { do sistema. Ajustes e complementação da } \\
\text { documentação do sistema. }\end{array}$ & $\begin{array}{l}\text { - Sistemas Testados com Respectivos } \\
\text { Relatórios e Documentação Técnica do } \\
\text { Sistema }\end{array}$ \\
\hline \multicolumn{3}{|c|}{6 - Integração e Implementação } \\
\hline $\begin{array}{l}6.1 \quad r \text { Desenvolvimento } \\
\text { Missão e Testes Finais do } \\
\text { VANT } \\
\text { - Coordenador } \\
\begin{array}{l}\text { Engenharia } \\
\text { Aeronáutica }\end{array} \\
\end{array}$ & $\begin{array}{l}\text { Ensaios de voo de inspeção das linhas de } \\
\text { transmissão, conforme missões especificadas. }\end{array}$ & $\begin{array}{l}\text { - Relatório de Ensaios de Missão } \\
\text { Piloto } \\
\text { Q Documentação do } \quad \text { Final } \\
\text { Qualification Review - FQR }\end{array}$ \\
\hline $\begin{array}{l}\text { 6.2 Implementação do } \\
\text { Sistema de Inspeção } \\
\text { - Coordenador de } \\
\quad \text { Engenharia }- \text { Inspeção }\end{array}$ & $\begin{array}{l}\text { Implementação do banco de dados de imagens e } \\
\text { telemetria, elaboração de manuais para inspeção } \\
\text { e criação dos relatórios de inspeção. }\end{array}$ & $\begin{array}{l}\text { - Manuais e Relatórios de Inspeção e } \\
\text { Banco de Dados de Imagens e } \\
\text { Telemetria Implantado }\end{array}$ \\
\hline $\begin{array}{l}\text { 6.3 Integração do Sistema } \\
\text { - Coordenador de TIC e } \\
\text { Imagem }\end{array}$ & $\begin{array}{l}\text { Testes, ajustes finais, implantação piloto e } \\
\text { homologação do sistema. }\end{array}$ & - Documentação do Sistema \\
\hline \multicolumn{3}{|c|}{7 - Comunicação e Transferência } \\
\hline $\begin{array}{l}\text { 7.1a Comunicação e } \\
\text { Gestão do Conhecimento } \\
\text { - Coordenador de Gestão } \\
\text { do Conhecimento }\end{array}$ & $\begin{array}{l}\text { Garantir o processo de geração, distribuição e } \\
\text { armazenamento de todas as informaçôes e } \\
\text { conhecimentos relativos ao projeto, de forma } \\
\text { acurada e consistente, por meios apropriados e } \\
\text { no momento certo, para os participantes } \\
\text { envolvidos ou afetados pelo projeto. }\end{array}$ & $\begin{array}{l}\text { Produtos de Comunicação } \\
\text { - Plano de Comunicação } \\
\text { - Apresentações } \\
\text { - Sumários } \\
\text { - Folders } \\
\text { - Banner e demais materiais eletrônicos, } \\
\text { do Inerge e do projeto }\end{array}$ \\
\hline $\begin{array}{l}\text { 7.1b Transferência do } \\
\text { Conhecimento } \\
\text { - Coordenador de Gestão } \\
\text { do Conhecimento }\end{array}$ & $\begin{array}{l}\text { Criar mecanismos e formas para que os } \\
\text { conhecimentos científicos gerados sejam } \\
\text { transferidos por meio de produção científica, } \\
\text { cursos, workshops, vídeos etc. }\end{array}$ & $\begin{array}{l}\text { Produção Científica } \\
\text { - } \quad \text { Artigos científicos } \\
\text { - } \quad \text { Dissertações de mestrado } \\
\text { - } \text { Monografias MBA } \\
\text { - Material de transferência de } \\
\text { tecnologia (cursos, workshop, vídeos, } \\
\text {...) }\end{array}$ \\
\hline $\begin{array}{l}7.2 \text { Transferência } \\
\text { Tecnológica } \\
\text { - Coordenador de Gestão } \\
\text { do Conhecimento }\end{array}$ & $\begin{array}{l}\text { Estruturar plano e criar mecanismos e formas } \\
\text { para que os conhecimentos técnicos gerados } \\
\text { sejam protegidos e transferidos por meio de } \\
\text { manuais, metodologias, produtos, patentes etc. }\end{array}$ & $\begin{array}{l}\text { Produção Técnica } \\
\text { - } \\
\text { - } \text { Banco de Imagem } \\
\text { Sistema de Gerenciamento de } \\
\text { - Informação } \\
\text { Sistema de Inteligência } \\
\text { Artificial para Previsão de Manutenção } \\
\text { Metodologias e Desenhos } \\
\text { - } \quad \text { Manuais técnicos e de inspeção } \\
\text { Patentes (em andamento e } \\
\text { registros) } \\
\text { Protótipo } \\
\text { Projeto aeronáutico } \\
\text { Relatório final do projeto }\end{array}$ \\
\hline \multicolumn{3}{|c|}{8 - Acompanhamento do Projeto } \\
\hline $\begin{array}{l}\text { 8.1 Gerência e } \\
\text { Acompanhamento do } \\
\text { Projeto } \\
\text { - Coordenador do Projeto }\end{array}$ & $\begin{array}{l}\text { Métodos, técnicas de gerenciamento que } \\
\text { possibilitem acompanhamento do desempenho } \\
\text { do projeto, contendo o realizado, comparação de } \\
\text { tempo e custo em relação ao planejado e a } \\
\text { projeção atualizada dos próximos passos, até a } \\
\text { conclusão do projeto. }\end{array}$ & $\begin{array}{l}\text { - Relatórios Gerenciais Mensais de } \\
\text { Acompanhamento do Projeto }\end{array}$ \\
\hline \multicolumn{3}{|c|}{9 - Gerenciamento do Projeto } \\
\hline $\begin{array}{l}\text { 9.1 Plano do Projeto } \\
\text { - Coordenador do Projeto }\end{array}$ & $\begin{array}{l}\text { Criar documento com descrição do plano do } \\
\text { projeto que possibilite identificar pré-requisitos, }\end{array}$ & $\begin{array}{l}\text { - Plano de Gerenciamento do Projeto e } \\
\text { seus Desdobramentos }\end{array}$ \\
\hline
\end{tabular}




\begin{tabular}{|l|l|l|}
\hline \multicolumn{2}{|c|}{} & $\begin{array}{l}\text { detalhar escopo do projeto, cronograma geral, } \\
\text { identificar as restrições, elaborar planos de } \\
\text { aquisição, qualidade, tratamento de riscos, de } \\
\text { recursos humanos. }\end{array}$ \\
\hline \multicolumn{2}{|c|}{$\mathbf{1 0}$ - Encerramento do Projeto } \\
\hline $\begin{array}{l}10.1 \text { Encerrar Projeto } \\
\text { Todos os integrantes do } \\
\text { projeto }\end{array}$ & $\begin{array}{l}\text { Documentar os resultados e formalizar as } \\
\text { entregas de produtos do projeto ao patrocinador } \\
\text { garantindo que eles reflitam as especificações } \\
\text { contidas na contratação. }\end{array}$ & $\begin{array}{l}\text { ・ Termo de Encerramento Assinado } \\
\text { • Relatório de Desempenho } \\
\text { - Documento de Entrega e Aprovação do } \\
\text { Projeto } \\
\text { - Ata de Encerramento }\end{array}$ \\
\hline
\end{tabular}

Figura 3 - Informações e conhecimentos vinculados às tarefas do cronograma do plano de gerenciamento do projeto Fonte: Elaborada pelos autores a partir do Plano de Gerenciamento do Projeto

Os documentos gerados vão além daqueles vinculados as etapas da metodologia de gerenciamento de projetos do PMBOK® (PMI, 2013) e contidos no Plano de Gerenciamento do Projeto (2014), razão pela qual um conjunto de pastas adicionais para armazenamento dos conhecimentos gerados são definidas.

\begin{tabular}{|c|c|c|}
\hline Pastas & Descrição & $\begin{array}{l}\text { Informações e Conhecimento Gerados } \\
\text { (Documentos Relacionados) }\end{array}$ \\
\hline $\begin{array}{l}\text { Documentos de } \\
\text { Reuniões }\end{array}$ & $\begin{array}{l}\text { Atas e documentos gerados em } \\
\text { reuniões. }\end{array}$ & $\begin{array}{ll}\text { - } & \text { Atas de Reuniões Técnicas } \\
\text { - } & \text { Atas de Reuniões de Acompanhamento do Projeto } \\
\text { - } & \text { Atas de Reuniões Ordinárias com a Celesc } \\
\text { - } & \text { Atas de Reuniões Extraordinárias com Celesc } \\
\end{array}$ \\
\hline Relatório de Viagens & $\begin{array}{l}\text { Registro das ações realizadas } \\
\text { em viagens de benchmarking, } \\
\text { apresentação de artigos em } \\
\text { eventos, visita a fornecedores } \\
\text { etc. }\end{array}$ & - $\quad$ Formulários de Registro de Viagem \\
\hline Biblioteca Virtual & $\begin{array}{l}\text { Repositório de arquivos em } \\
\text { diferentes formatos (textos, } \\
\text { sons, vídeos etc.) visando ao } \\
\text { compartilhamento de arquivos } \\
\text { de livros, podcasts, vídeos, } \\
\begin{array}{lr}\text { apostilas, manuais, } \\
\text { apresentações, pesquisas } \\
\text { correlatas aos temas do projeto } \\
\text { etc. }\end{array}\end{array}$ & $\begin{array}{ll}\text { - } & \text { Texto } \\
\text { - } & \text { Sons } \\
\text { - } & \text { Vídeos } \\
\text { - } & \text { Links } \\
\text { - } & \text { Aprosostilas } \\
\text { - } & \text { Manuais } \\
\text { - } & \text { Apresentações } \\
\text { - } & \text { Pesquisas Correlatas aos Temas do Projeto } \\
\end{array}$ \\
\hline Repositório de e-mail & $\begin{array}{l}\text { Mensagens de e-mail trocadas } \\
\text { entre os participantes do projeto } \\
\text { e entre os participantes do } \\
\text { projeto e empresas parceiras, } \\
\text { entre outros. }\end{array}$ & $\begin{array}{ll}\text { - } & \text { Entre Integrantes Projetos } \\
\text { - } & \text { Entre Integrantes do Projeto e Celesc } \\
\text { - } & \text { Entre Gestores do Projeto e Celesc } \\
& \text { Integrantes Projetos / Empresas Fornecedoras }\end{array}$ \\
\hline Lições Aprendidas & $\begin{array}{l}\text { Erros, acertos e fatores que } \\
\text { determinaram o sucesso ou } \\
\text { fracasso do projeto. }\end{array}$ & - $\quad$ Formulários de Registro de Lições Aprendidas \\
\hline Páginas Azuis & \begin{tabular}{lcc|} 
Cadastro & de & especialistas \\
externos, pessoas & físicas ou \\
jurídicas. & &
\end{tabular} & - Formulários de Registro de Páginas Azuis \\
\hline Melhores Práticas & $\begin{array}{l}\text { Registro das melhores práticas } \\
\text { decorrentes do projeto, no qual } \\
\text { deverão constar fatos e } \\
\text { resultados relevantes. }\end{array}$ & $\begin{array}{ll}\text { - } & \begin{array}{l}\text { Formulários de Registro das Melhores Práticas Decorrentes } \\
\text { do Projeto }\end{array} \\
\text { - Vídeos de Registro das Melhores Práticas Decorrentes do } \\
\text { Projeto }\end{array}$ \\
\hline $\begin{array}{l}\text { Modelo de } \\
\text { Formulários }\end{array}$ & 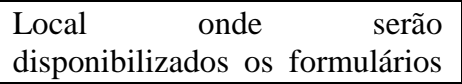 & $\begin{array}{ll}\text { - } & \text { Modelo de Ata de Reuniões } \\
\text { - } & \text { Modelo de Relatório }\end{array}$ \\
\hline
\end{tabular}




\begin{tabular}{|c|c|c|}
\hline (Impressos) & a serem utilizados no projeto. & $\begin{array}{l}\text { - } \text { Modelo de Relatório de Viagem } \\
\text { - } \quad \text { Modelo de Melhores Práticas } \\
\text { - Modelo de Lições Aprendidas } \\
\text { - Modelo de Registro Equipe do Projeto - Base de } \\
\text { - Competências } \\
\text { - Modelo de Solicitação de Mudanças etc. }\end{array}$ \\
\hline
\end{tabular}

Figura 4 - Informações e conhecimentos - pastas adicionais Fonte: Elaborada pelos autores

O plano foi construído tem como a base na metodologia do PMBOK® (PMI, 2013) e no Plano de Gerenciamento do Projeto (2014).

A abordagem funcionalista apoia a organização do conhecimento explícito por meio de relatórios, atas, manuais técnicos e de inspeção, artigos científicos, banco de imagem, sistemas de informação, projetos e protótipos, lições aprendidas, páginas azuis, páginas amarelas, melhores práticas, dentre outros, enquanto que a abordagem interpretativa se ocupa da criação de um ambiente de interação tanto com os integrantes do projeto, como com a Celesc por meio de reuniões presenciais e/ou uso de call conference, workshops internos e com a empresa contratante e que constam do Plano de Comunicação não apresentado no presente texto.

Foram valiosos também os estudos dos Manuais de Frascati (2013), de Oslo (2004), da Aneel (2012) e da Lei 11.196/05 - Lei do Bem (2015), para compreender os tipos de pesquisa utilizadas em P\&D.

Os estudos de Shinoda (2012), Carneval, Nascimento e Pereira (2005) e Alves (2015) foram importantes na definição das práticas e ferramentas utilizadas no Plano de Gestão da Informação e do conhecimento.

\subsubsection{Tecnologia da informação}

A tecnologia da informação exerce um papel essencial tanto no armazenamento do conhecimento explícito, por meio da estruturação de repositórios e bases de informação, como na conexão dos integrantes do projeto, possibilitando a interação face a face e a criação de uma visão compartilhada.

Visando a dar suporte à implantação do PGIC foi selecionado o software Redmine por trata-se de software livre e flexível, gratuito, baseado na web e incluir gerenciador de tarefas, calendário e ferramentas para criar gráficos de Gantt, o que ajuda na representação visual dos projetos e seus prazos de entrega, mostrando as metas de cada fase do projeto, documentos e gerenciamento de arquivos, gerenciamento de tempo, além de ser multiplataforma e incluir outros recursos como forum, wiki, ter uma interface simples e agradável além de uma equipe ativa de desenvolvimento e melhoria do produto.

\section{CONSIDERAÇÕES FINAIS}

Além das práticas e ferramentas de Gest

Existem muitos modelos teóricos e práticos de Gestão do Conhecimento para as organizações, mas ainda são poucos os estudos que tratam da Gestão do Conhecimento para Projetos, e mais raros ainda os voltados para projetos de P\&D.

Ao finalizar este estudo pode-se entender, com base em Shinoda (2012), a importância do interrelacionamento da área de Gestão do Conhecimento com a de Gestão de Projetos. A Gestão do Conhecimento contribui para a Gestão de Projetos por meio da sistematização da informação e do conhecimento em um único espaço, apoiando a criação e o compartilhamento do conhecimento e, por meio da criação da memória do projeto, facilitando a transferência do conhecimento. Os projetos também trazem benefícios à Gestão do Conhecimento por serem veículos de criação de informações e conhecimentos na organização que precisam ser gerenciados.

Pode-se também considerar que, apesar de a Gestão do Conhecimento não ser um processo explícito na metodologia de gerenciamento de projetos do guia PMBOK® (PMI, 2013), sua prática não deixa de estar contemplada no processo de comunicação e no apêndice X1. Contudo, vale destacar que a criação de um processo ou a ampliação do processo de comunicação poderá contribuir de forma mais efetiva para a definição de práticas de Gestão do Conhecimento na metodologia de Gestão de Projetos.

Como considerações finais destacam-se como variáveis de suma importância para o sucesso da Gestão do Conhecimento em Projetos a tecnologia de informação acessível a todos os integrantes do projeto por diferentes meios, intranet e extranet, e o envolvimento da equipe.

No presente momento ainda não é possível apresentar resultados efetivos e responder à questão de pesquisa - a Gestão do Conhecimento, por meio da definição de um plano de gestão da informação e do conhecimento, pode contribuir para a transferência dos conhecimentos gerados em projetos de pesquisa e desenvolvimento intraprojetos e interorganizacionais? em razão de esse plano estar implantado há pouco tempo e o projeto estar com apenas um terço de seu tempo de execução.

Pode-se inferir, contudo, que sistematizar 
informações e conhecimentos em um único ambiente tecnológico apoiará o desenvolvimento dos processos de criação, aquisição, compartilhamento, armazenamento, (re)utilização, proteção e transferência das informações e conhecimentos. Um foco especial é dado ao processo de transferência de informações e conhecimentos por tratar-se de um projeto interorganizacional que, ao seu final, deverá permitir a transferência das informações e conhecimentos da empresa executora para a empresa patrocinadora / cliente.

Como recomendações para trabalhos futuros sugere-se a definição de planos de transferência do conhecimento que podem ter o foco intraorganização e/ou interorganizacional; e um estudo que aborde as diferenças e semelhanças entre Gestão de Conhecimento para organizações e Gestão de Conhecimento para projetos.

\section{REFERÊNCIAS}

ANEEL. Agência Nacional de Energia Elétrica (Brasil) (2012) - Manual do Programa de Pesquisa e Desenvolvimento Tecnológico do Setor de Energia Elétrica. Agência Nacional de Energia Elétrica. Brasília: ANEEL. Recuperado em 03 set. 2015 de: http://www.aneel.gov.br/aplicacoes/leitura_arquivo/ default.cfm?idaplicacao $=56$.

Blog edutrevizan. Recuperado em 16 ago. 2015 de: https://edutrevizan.wordpress.com/2013/09/25/10softwares-interessantes-para-gestao-de-projetos/.

Carneval, P. P. O., Nascimento, W. R., \& Pereira, Y. A. H. (2005). Gestão do conhecimento aplicada ao gerenciamento de projetos. Trabalho de Conclusão de Curso para a obtenção de Grau de Especialista em Gerenciamento de Projetos. MBA em Gerenciamento de Projetos. Universidade Federal Fluminense, Niterói.

Choo, C. W. (2006). A organização do conhecimento: como as organizações usam a informação para criar conhecimento, construir conhecimento $e$ tomar decisões (2. ed.). São Paulo, Senac São Paulo.

Davenport, T. H., \& Prusak, L. (1998) Conhecimento Empresarial: como as organizações gerenciam o seu capital intelectual. Rio de Janeiro, Campus.

Dhaliwal, J., \& Benbasat, I. (1996). The use and effects of knowledge-based system explanations: theoretical foundations and a framework for empirical evaluation. Information Systems Research, 7, pp. 243-361.

George, J. F., Iacono, S., \& Kling, R. (1995). Learning in context: extensively computerized work groups as communities of practice. Accounting, Management and Information Techgnologies, 5, pp.185-202.

Faraco, R. A., Mussi, C. C., Angeloni, M.T. (2014). Social Networks and Knowledge Transfer in Technological Park Companies in Brazil. Journal of Technology Management \& Innovation, v. 9, p. 172-186.

Jamil, G. L. (2005). Gestão de informação e do conhecimento em empresas brasileiras: estudo de múltiplos casos. Tese. Programa de Pós-Graduação em Ciência da Informação. Universidade Federal de Minas Gerais.

BRASIL. Lei 11.196/05 - Lei do Bem, de 21 de novembro de 2005. Trata da concessão de incentivos fiscais às pessoas jurídicas. Recuperado em 17 nov. 2014 de: <http://www.planalto.gov.br/ccivil_03/_ato20042006/2005/lei/111196.htm.

Malhotra, Y. (1993). Role of information technology in managing organizational change and organizational interdependence. New York, NY, Global Risk Management Network, LLC Available at: www.brint.com/papers/change/.

Nonaka, I., \& Takeuchi, H. (1997). Criação do Conhecimento na Empresa. Rio de Janeiro, Campus.

OECD, OCDE e FINEP (2015). Organização para Cooperação e Desenvolvimento, Organização para a Cooperação e Desenvolvimento Econômico, Financiadora de Estudos e Projetos (2005) Manual de Oslo - Proposta de Diretrizes para Coleta e Interpretação de Dados sobre Inovação. Financiadora de Estudos e Projetos. Rio de Janeiro : ART/FINEP. Recuperado em 14 set. 2015 de: http://download.finep.gov.br/imprensa/manual_de_ oslo.pdf.

OCDE. Organização para a Cooperação e Desenvolvimento Econômico (2013) - Manual de Frascati - Metodologia proposta para definir Inquéritos sobre Investigação e Desenvolvimento Experimental. Coimbra : F-Iniciativas. Recuperado em 14 set. 2015 de: http://www.mct.gov.br/upd_blob/0225/225728.pdf.

Pereira, A. P., Caciglieri Junior, O. (2015). MOP\&D: Modelo de desenvolvimento integrado de produto orientado aos projetos de P\&D do setor elétrico brasileiro. Espaço Energia. Out. Recuperado em 29 de dez. 2015 de: http://www.espacoenergia.com.br/edicoes/23/EE02 3-09-12.pdf.Pinheiro, A. A., Siani, A. C.; Guilhermino, J. F., Henriques, M. G. M. O., 
Quental, C. M., \& Pizarro, A. P. (2006). Metodologia para gerenciar projetos de pesquisa e desenvolvimento com foco em produtos: uma proposta. Revista de Administração Pública, 40(3), may-jun.

Prado, D. (2009). Gerenciamento de portfólios, programas e projetos nas organizações. Nova Lima, INDG Tecnologia e Serviços.

Plano de Gerenciamento do Projeto (2014). Projeto desenvolvimento de metodologia e sistema para tratamento de imagem e reconhecimento de padrões para inspeção autônoma de linhas aéreas de transmissão e de distribuição. ANEEL / INERGE.

PRJ. (2014) Arquivo referente ao formulário de Projeto desenvolvimento de metodologia e sistema para tratamento de imagem e reconhecimento de padrões para inspeção autônoma de linhas aéreas de transmissão e de distribuição. ANEEL / INERGE.

Project Management Institute (2013). Um Guia do Conhecimento em Gerenciamento de Projetos (Guia PMBOK®) (5. ed.). Newtown Square, Pennsylvania, USA, PMI.

Shinoda, A. C. M. (2012). Gestão do conhecimento em projetos: um estudo sobre conhecimentos relevantes, fatores influenciadores e práticas em organizações projetizadas. Dissertação (Mestrado). Universidade de São Paulo, São Paulo.
Smit, J., \& Talamo, M. F. (2007). Da impropriedade acadêmica de usar o termo gestão do conhecimento na opinião dos programas de Ciências da Informação. Revista de Ciência da Informação, 3 (5), out.

Stenmark, D. (2001). Leveraging tacit organizational knowledge. Journal of Management Information Systems, 17, p. 9-24, 2001.

Vargas, R. V. (2006). Gerenciamento de projetos: estabelecendo diferenciais competitivos (6. ed.). Rio de Janeiro, Brasport.

Vicente, L. (s. d.). Como escolher um software de gerenciamento de projetos? Recuperado em 16 ago. 2015 de: http://blog.luz.vc/como-fazer/comoescolher-um-software-de-gestao-de-projetos/.

Vieira, M. F. (2008). Guia Para Implementação de Ferramentas de Gestão de Projetos. Revista Mundo PM - Project Management, 7 jan.

Von Krogh, G., Ichijo, K., \& Nonaka, I. (2001). Facilitando a criação de conhecimento: Reinventando a empresa com o poder de inovação contínua. Rio de Janeiro, Campus.

Yin, R. K. (2010). Estudo de Caso - Planejamento e Métodos- (4. ed.). São Paulo, Bookman.

Zhao, J. L., Kumar, A., \& Stohr, E. A. (2001). Workflow-centric information distribution through e-mail. Journal of Management Information Systems, 17, pp. 45-72. 